\title{
A Visão Sensível como IMagem da VISÃo DOS INTELIGÍlEIS
}

\author{
Alice Bitencourt Haddad ${ }^{1}$
}

RESUMO: O artigo pretende explicitar em que consiste a visão (ópsis) na República de Platão, usada pelo filósofo como imagem que ajudaria a fazer compreender o que ele entende por conhecimento de Ideias.

PALAVRAS-CHAVE: Platão. República. Visão. Percepção.

No livro VI da República, Sócrates oferece, no lugar de uma explicação acerca do Bem, uma exposição do que lhe parece seu filho, o Sol, tomando-o como análogo ao Bem, atuando, no âmbito dos visíveis, de modo semelhante ao Bem no âmbito dos inteligíveis. A analogia pressupóe, todavia, uma interpretação de como se opera a visáo, rigorosamente falando, a visão sensível (sendo redundante para ser clara), que é, também e não por acaso, bastante propícia para sua exposição. Na República, podemos extrair uma teoria da percepção e da visão especificamente, embora pouco elaborada, porém, que será confirmada pelo Timeu, ao menos parcialmente, e que difere, entretanto, de outras, além daquelas exploradas pelo próprio Platão em alguns diálogos, como o Teeteto e o Mênon, quando da apresentação de posiçôes a serem refutadas pelo filósofo. A estratégia platônica na República, portanto, de usar uma imagem aparentemente simples, a visão, para ilustrar o processo de conhecimento, é eficiente no sentido de que tendemos a não questionar o argumento no que tange à exposiçáo acerca da visão dos sensíveis, e daí

\footnotetext{
${ }^{1}$ Professora de Filosofia do Departamento de Filosofia do Instituto de Ciências Humanas e Sociais da Universidade Federal Rural do Rio de Janeiro e do Programa de Pós-Graduação em Lógica e Metafísica da Universidade Federal do Rio de Janeiro; Pesquisadora do Zétesis da UFRRJ e do PRAGMA-UFRJ.
} 
já estamos comprometidos com uma certa interpretação da realidade, ao passarmos para a compreensão do que seria a visão dos inteligíveis. É isso que pretendemos defender neste trabalho, começando por entender, a partir principalmente da República, mas com o apoio do Timeu e do Teeteto, o que seria uma teoria da visão platônica, para entáo proceder ao estabelecimento de um contraste com outras teorias discrepantes, com fins meramente didáticos, ilustrativos da singularidade da proposta do filósofo.

\section{A VISÁ̃ E A AUdiÇÃo COMO POTÊNCIAS (DYNÁMEIS)}

No livro V, o tema ocorre pela primeira vez, em 477, quando da discussão acerca da diferença entre o filósofo e o filodoxo. A visão e a audição aparecem como exemplares do que seriam dynámeis. $\mathrm{O}$ texto diz:

Dizemos que são potências (dynámeis) um gênero dos seres (génos ti tôn ónton) por meio dos quais nós agora podemos o que podemos (dynámetha hà dynámetha), e tudo o mais que puder algo. Por exemplo, digo que estão entre as potências a visão (ópsin) e a audição (akoèn), se compreendes o que quero dizer com essa ideia.

Compreendo, disse.

Escuta, então, o que me parece acerca delas. Pois eu mesmo não vejo (horô), na potência, nem uma cor (khróan) nem figura (skhêma), nem nada como tal, como [o que encontramos] em muitas outras coisas: aquilo para o que mirando o olhar (apoblépon) distingo (diorizomai), afora mim mesmo, que umas coisas são assim e outras não. Na potência olho apenas aquilo pelo que é e produz (eph'hôi te ésti kaì hò apergázetai), e chamei cada uma delas de potência por isso, e chamo de a mesma [potência] aquela que é voltada para o mesmo e que produz o mesmo (tèn mèn epì tôi autôi tetagménen kaì tò autò apergazoménen), enquanto chamo de outra a que é voltada para outra coisa e realiza outra coisa. (República, $477 \mathrm{c} 1-\mathrm{d} 5)^{2}$.

As potências são, assim, seres que não são discerníveis por alguma qualidade visível, mas por aquilo que elas produzem, realizam. A visão e a audição são potências presentes em nós, mas que são diferentes: não são voltadas para o mesmo e não produzem o mesmo. Em República VI, 507c, Sócrates precisará: por meio da vista, vemos as coisas visíveis (tà horómena) e, por meio da audição, as coisas audíveis (tà akouómena). Estas não são consideradas por Platão $o$ mesmo. O sensível em si mesmo não é considerado

\footnotetext{
${ }^{2}$ Esta e as demais traduçōes são nossas.
} 
aqui de maneira íntegra. Embora vejamos e ouçamos uma banda que passa, não é a banda, nem o conjunto de músicos, homens com seus instrumentos, que formam a banda que é tomado como aquilo que vemos e ouvimos. Em $507 d$, é a cor que aparece como aquilo que a vista vê. Em 508c, os olhos que se dirigem às cores náo iluminadas pela luz do dia, mas por claróes noturnos, são caracterizados como aqueles que veem mal (amblyóttousi) e que parecem quase cegos (engùs phaínontai typhlôn).

São poucos os exemplos que temos, contudo, podemos, pela caracterização que Platão faz da visão como potência, e como potência distinta da audição, perceber em sua teoria da visão aquilo que posteriormente Aristóteles vai chamar de sensível próprio, cabendo à visão a cor, à audição o som, ao paladar o sabor, náo podendo o sensível próprio ser percebido senáo pelo seu respectivo órgáo do sentido, e a respeito do qual este nunca se engana (De Anima, II, 6).

Em apoio a essa tese temos o Teeteto, no momento em que Sócrates examina criticamente a ideia de que o conhecimento (epistéme) seja sensação (aisthesis - 184b et seq.). Ele e Teeteto concordam que o homem vê o branco e o preto por meio dos olhos (ómmasi) e que ouve os agudos e os graves por meio das orelhas (osin); consideradas a visão e a audição também como dynámeis (184e7), por meio das quais se percebem coisas diferentes, sendo impossível perceber o que é próprio a uma pela outra. E, se pensamos (o verbo usado é dianoéo) algo que envolva ambas as percepçóes, não é nem por meio da vista nem por meio da audição que ele é percebido. Sócrates fala, em 186b-c, que os homens e as bestas por natureza ( $p$ hýsei), assim que nascem (euthìs genoménois), podem perceber tudo que, por meio das afecções corporais (tô̂u sómatos pathémata), tende (teínei) para a alma, não residindo o conhecimento nessas afecçóes, mas no raciocínio (syllogismôi) em torno delas. Não nos interessa aqui, a rigor, o problema do que seja epistéme, no entanto, de todo modo, o que fica claro é que os diferentes órgãos dos sentidos percebem de maneira particular o sensível que lhes é próprio. Já a semelhança e a dissemelhança, a identidade e a diferença, a unidade e a multiplicidade, o ser e o não ser são chamados de "comuns" (koina $\left.a^{3}\right)$ por Platão, comuns aos diferentes sensíveis, e não são percebidos por um órgão próprio. É a alma, por meio dela mesma, que os examina (episkopeîn). Em outras palavras, quem faz a reunião das diferentes percepçôes não é nenhum órgão do corpo, mas é já

3 Ver interessante análise e comparação do uso de koiná por Platáo com o de koinè aisthesis por Aristóteles, em BEARE (1906, p. 260-263). 
a alma. A percepção, portanto, de uma coisa qualquer que é visível, audível, tangível, por exemplo, não é atribuição somente de órgãos corporais, dos chamados órgãos dos sentidos. Ela exige mais do que eles, na medida em que o reconhecimento dela (da "coisa” sensível) por nós não se dá como a representação de um amontoado de impressôes distintas, mas ela nos aparece como coisa una, existente, com todas as suas qualidades sensíveis reunidas de maneira harmônica.

\section{A PRIMAZIA DA VISÃo SOBRE OS DEMAIS SENTIDOS E SUA COMPARAÇÃo COM O SOL}

Em República VI, 507c, diz Sócrates que o artífice dos sentidos fabricou de maneira mais dispendiosa (polytelestáten) a potência de ver e ser visto (horân e horâsthai). Isso porque ela seria a única que demandaria a presença de um terceiro gênero de coisas, além dos próprios olhos, onde se encontra a vista, e das próprias coisas, que são os visíveis. A vista nada verá e as cores serão invisíveis enquanto não houver luz .

Tal particularidade não é considerada um obstáculo, algo que faria da visão um sentido deficitário, pior. Pelo contrário, a luz é considerada o liame $\left(z_{\text {zyón }}{ }^{5}\right)$ mais honorável (timióteros) de todos, atribuindo-se ao Sol (hélios) uma soberania sobre os demais deuses do céu em sua produçáo. E, o mais interessante para o nosso assunto, a analogia que antes era circunscrita ao Sol e ao Bem, agora se estende aos olhos (ómma). São eles, dos órgãos dos sentidos, os mais helioeidéstaton, os mais semelhantes ao sol. Pode-se ver aí não apenas a comparação dos formatos, esféricos em ambos, mas uma comparação também daquilo que ambos produzem. Sócrates, em 508b, diz, muito brevemente, que a dýnamis (o poder) que os olhos possuem, depositada pelo sol, é como uma corrente, como algo que do sol derrama, ou que do sol transborda (epirryton). Sócrates não o diz em momento algum, porém, a descrição nos leva a imaginar que alguma luz derivada do sol existe nos próprios olhos, como se os olhos fossem, para nós, pequenos sóis.

\footnotetext{
${ }_{4}^{4}$ Nota Adam (1980, v. 2, nota ad 507c20) que, apesar de muitos acusarem Platão de desprezar nesse passo o fato de a audiçáo precisar do ar como meio para ocorrer (o que não acontece no Timeu), o que o autor estaria propondo seria apenas um quadro mais geral do que experimentamos: enquanto podemos ouvir, tocar etc. tanto na claridade quanto na escuridão, nós só podemos ver onde há luz.

5 zygón é um termo forte para significar esse liame. Ver, por exemplo, em BAILLY (2000), outros exemplos de zygá, como as imagens do jugo de bois e cavalos, do banco de remadores que atravessa o navio de lado a lado, do braço de uma balança, da fileira de soldados, entre outras.
} 
No Timeu, temos essa mesma ideia, mas de forma bem explícita, quando da narrativa da confecçáo dos olhos pelos deuses (45b-46a). Os olhos são ali caracterizados, logo de início, como phosphóra, o que leva ou o que dá a luz. Segundo a descrição de Timeu, dentro de nós havia um fogo puro (eilikrinés), que os deuses fizeram correr através dos olhos, todo unido e denso (leîon kai pyknón),

Eles ainda comprimiram o centro dos olhos ${ }^{6}$, de modo que ali só pudesse correr o fogo puro (katharòn). Então, quando a luz do dia (methemerinòn ... phôs) se encontra em torno da corrente da visão (tò tês ópseos rhêuma), ali o semelhante dá de encontro com o semelhante (tóte ekpîpton hómoion pròs hómoion), fundindo-se com ele (sympagès genómenon), formando um único corpo (hèn soma) homogêneo, na direção da linha dos olhos, de modo que a corrente que flui de dentro, ao oferecer pressão, se condensa na corrente que vem do exterior. Quanto toda a corrente da visão, submetida às mesmas afecçóes pela similitude de suas partes, toca em algo ou é tocada, transmite todos os movimentos através do corpo até a alma (eís hápan tò sôma mékhri tês psykhês), proporcionando essa percepção (aisthesin) pela qual ora dizemos ver (horân). Retirando-se à noite o fogo aparentado (tôे syngenoûs pyròs), o fogo [interno] é interceptado; encontrando à sua saída o dissemelhante, altera-se e se apaga, deixando de ser da mesma natureza (symphyés) que o ar circundante, que não tem mais o fogo. Assim, para de ver e leva ao sono; pois tendo os deuses maquinado a proteçáo da vista (soterían... tês ópseos), a natureza das pálpebras (tèn tôn blepháron phýsin), quando estas se fecham, aprisionam o poder do fogo do interno (katheírgnysi tèn toû puròs entòs dýnamin), o qual, por outro lado, dispersa e acalma os movimentos internos, os quais, por sua vez acalmados, levam ao repouso (hesykhia). Sendo o repouso profundo, cai-se em sono de breves sonhos; mas quando subsistem movimentos mais fortes, dependendo de sua natureza e dos lugares onde resistem (hoîai kaì em hoíois àn tópois leipontai), suscitam outras tantas imagens internas assemelhadas às de fora $^{7}$, das quais nos recordamos ao acordar (toia $\hat{t a ~ k a i ̀ ~ t o s a u ̂ t a ~ p a r e ́ s k h o n t o ~}$ aphomoiothénta entòs éxo te egertheîsin apomnemoneuómena phantásmata).

${ }^{6}$ Há um consenso entre tradutores e intérpretes de que aqui se trata da pupila. Ver, por exemplo, CORNFORD, [1937?], além de ARCHER-HIND (2002, p. 157).

${ }^{7}$ Essa passagem do texto encerra enorme dificuldade e por isso lhe demos destaque na transliteração. A questáo é como entender a relaçáo entre os termos aphomoiothénta, entós, éxo e phantásmata. Rivaud (em PLATON, 1985) traduz "[...] semblables à de objets intérieurs ou extérieurs et dont nous conservons souvenance au réveil", entendendo aphomoiothénta aplicado de forma geral a entós e éxo. Por outro lado, toma entós e éxo não aplicados a phantásmata, mas a "coisas", "objetos". Brisson (em PLATON, 2001) traduz "[...] qui sont de représentations intérieures et des souvenirs de choses extérieurs dont on a fait l'expérience à l'état de veille", entendendo aphomoiothénta ligado a entós e éxo ligado a apomnemoneuómena. Carlos Alberto Nunes (em PLATÂO, 2001) tem uma solução bem diferente: “[...] suscitam no nosso íntimo [entendendo entós como "dentro de nós" e ligado a 
Pode-se notar no Timeu que essa ideia de um transbordamento da luz do sol para os olhos reaparece e numa descrição bem mais rica do que na República. Enquanto na República não parece ser o caso, pelo menos isso não é explicitado, que os olhos possuam uma luz própria, no Timeu nós temos três espécies de luz envolvidas no processo de ver: (i) a luz dos olhos, caracterizada como um fogo puro, denso, uniforme, que não se espalha, que não queima; (ii) a luz do dia, o fogo originador da luz dos olhos, por isso chamado de irmão (adelphón - 45b7) e aparentado (tô̂ syngenoûs - 45d3), caracterizado também como um fogo que não queima, de luz branda, e descrito como um corpo fabricado pelos deuses (oikeîon hekástes heméras sôma - o corpo próprio de cada dia - 45b5-6). Essa caracterização da luz como um corpo se mantém, como pudemos observar, no encontro da corrente dos olhos com a corrente exterior, que formam também um corpo homogêneo. A imagem pode nos parecer estranha, mas a ideia é a de que esse corpo formado pelo fogo visual e pelo fogo do dia é uma extensão do nosso próprio corpo: Timeu diz, em 64d, que ele, durante o dia (kath' heméran), se torna symphyès hemôn, "naturalmente unido a nós", "atado a nós". E a afecção corporal da visão se dá ali e não dentro da vista ou dentro de alguma parte daquilo que consideramos, corriqueiramente, como nosso corpo $^{8}$. (iii) Ainda podemos falar de uma terceira espécie de luz, aquela que provém das coisas mesmas. O que garante a existência, em Platão, dessa luz própria às coisas é a descrição que o filósofo faz das cores, como "[...] chamas que emanam de cada um dos corpos (phlóga tôn somáton hekáston aporréousan), e de partes proporcionais à vista de modo a ocorrer a percepção"(67c6-8). Note-se, todavia, que essa luz não é suficiente para tornar esses corpos visíveis na ausência de uma outra luz interveniente, isto é, na escuridão9 . Aqui se mantém a ideia, só para recordarmos esse ponto que já abordamos na República e no Teeteto, de que a visão é a percepção de cores. E aí, voltando ao Timeu, temos uma longa descrição da origem da percepção das cores por meio do impacto provocado pelo encontro da luz das coisas com a luz dos olhos (Timeu, 67c-68d).

\footnotetext{
phantásmata] outras tantas imagens da mesma natureza, de que nos lembramos quando acordamos para o mundo exterior [entendendo éxo desvinculado de phantásmata]". Archer-Hind (2002) tem uma solução parecida, mas mantém a vinculaçáo de éxo com phantásmata, da seguinte forma: "[...] which are images within us, and when we awake are remembered as outside us".

${ }^{8}$ Essa questão é bem explicada, em nota, em ARCHER-HIND (2002, p. 156-157).

9 Essa é uma boa observação de Rivaud (em PLATON, 1985, p. 104), que resolve uma suposta incompatibilidade entre a teoria da visão do Timeu e a da República, nâo atribuindo às cores a causa da visibilidade dos objetos. Em ambos os diálogos, desde a interpretação de Rivaud, a luz do sol ou do dia é fundamental para a ocorrência da percepção visual.
} 
Com relação à primazia da visão sobre os demais sentidos, que já aparecia na República, o Timeu também nos oferece suficiente apoio. Há, não só no Timeu como no Fédon, e provavelmente em outros diálogos de maneira mais ou menos ostensiva, certo desprezo do filósofo pelas explicaçóes mecânicas dos fenômenos. Para usar uma terminologia aristotélica, uma recusa das causas motrizes e materiais como as verdadeiras razóes de um determinado fenômeno. Após apresentar a visão dentro desses parâmetros, Timeu afirma que todas essas causas são apenas secundárias, acessórias, synaítia. E que o mais importante é tratar da utilidade da visão, daquilo que o deus tinha em vista ao nos presentear com ela. A defesa que ele faz da visão, apesar de um pouco longa, vale a pena citar:

A visão (ópsis), até então, segundo minha opiniáo, veio a ser para nós a causa da mais importante utilidade (aitía tês megistes ophelias), porque dos discursos atuais acerca do universo (tôn nûn lógon perì tồ pantòs), nenhum poderia ser proferido sem que se vissem os astros (ástra), o sol (hélion) e o céu (ouranòn). Mas agora, tanto o dia quanto a noite, ao serem vistos, bem como os meses, as revoluçóes dos anos, os equinócios e solstícios proporcionando a invenção do número (memekhánetai mèn arithmón), ofereceram a concepçáo do tempo (khrónou dè énnoian) e a investigação acerca da natureza do universo (perí te tês toû pantòs phýseos zétesin); daí abrimos passagem ao gênero da filosofia (eporisámetha philosophias génos), em relaçáo ao qual nenhum bem maior (meîzon agathòn), dado pelos deuses (dorethèn ek theôn), veio nem virá um dia ao gênero mortal. Digo então que isto é o maior bem dos olhos (ommáton mégiston agathón); das outras coisas menores o que celebraríamos? Quem não é filósofo (ho mè philósophos), privado da visão dessas coisas, queixandose lamentaria em vão. Mas que seja dito por nós acerca disso que esta é a causa em vista do quê (epi taûta aitía): que o deus inventou de nos presentear com a visão a fim de que, ao examinarmos as revoluçóes da inteligência no céu (tàs en ouranôi tồ nồ katidóntes periódous), nos servíssemos delas para as revoluçōes de nosso pensamento (khresaimetha epì tàs periphoràs tàs tês par' hemîn dianoéseos), sendo estas de mesma origem (syngeneîs) que aquelas, passando de desordenadas a ordenadas (ataráktois tetaragménas), após aprender a adquirir a correção natural dos cálculos (logismôn katà phýsin orthótetos), imitando (mimoúmenoi) aquilo que, próprio ao divino, é totalmente estável (pántos aplaneîs), para que o estabeleçamos naquilo que em nós é errante (tàs en hemin peplaneménas katastesaimetha). (Timeu, 47a1-c4).

A visão sensível, no Timeu, portanto, aparece como condição para a existência da própria filosofia. Na República, sua importância também é destacada numa passagem muito próxima a essa do Timeu, embora bem mais 
sintética, ao final do livro IX, no contexto da discussão acerca dos prazeres e da felicidade do ponto de vista do homem e não mais da cidade. Após a constatação de Gláucon de não se encontrar em lugar nenhum a cidade construída pelos personagens, complementa Sócrates (592b1-2):

Mas, disse eu, talvez (isos) se encontre no alto do céu (en ouranôi... anákeitai) um paradigma (parádeigma) para quem quiser ver e construir-se a si mesmo (heautòn katoikizein) por meio do que viu (horônti).

Entendendo, evidentemente, esse céu do texto da República como o céu estrelado, o mesmo céu de que se trata no Timeu, sem extrapolaçóes para além do mundo físico, a visão é também aqui uma condição, certamente não a única, mas uma importante condição para figurar nos dois diálogos, para a organização da alma. A visão do céu nos ensina o número, o tempo, enseja a investigação sobre o todo e mostra a regularidade e a estabilidade de que precisamos para ordenar nosso pensamento (dianóesis, como aparece no Timeu) e para estabelecer em nós mesmos o paradigma de excelência construído e revelado ao longo da República.

\section{Teorias discrepantes da visÃo E os pressupostos da interpretaÇÃo PLATÔNICA}

Esta seção visa a abordar apenas duas teorias da visão cuja defesa viria a confrontar a teoria platônica, e que certamente não poderiam ser usadas como análogas à visão inteligível. Elas são apresentadas aqui, como frisamos anteriormente, meramente com fins ilustrativos, didáticos, no sentido de evidenciarem alguns pressupostos da descrição que Platão faz da visão, especialmente na República. Elas não são apenas reveladoras dos pressupostos platônicos, como mostram que eles são passíveis de recusa:

\subsection{AQUILO QUE VEMOS SE REFERE A SENSÍVEIS CUJA EXISTÊNCIA NÃO SE COLOCA EM DÚVIDA}

$\mathrm{Na}$ República, as cores, que constituem o próprio visível, são tomadas como pertencentes a coisas que náo deixam de ser tomadas como existentes ou presentes, quando deixam de ser vistas. Isso fica claro pela passagem 508c6-9: 
Quanto aos olhos (ophtalmoî), disse eu, sabes que, quando alguém não mais os dirige para aquelas coisas cujas cores a luz diurna (tò hemerinòn phôs) mantém, mas para aquelas que recebem clarôes ${ }^{10}$ noturnos (nykterinà phénge), eles ficam com a vista fraca e parecem próximos de ficarem cegos, assim como se não existisse mais neles a visão pura (katharâs ópseos)?

Sócrates fala de coisas mal ou bem iluminadas, cuja visão apenas depende da luz. $\mathrm{Na}$ ausência desta, não são as coisas que são consideradas deformadas, desintegradas ou destituídas de alguma realidade, contudo, os olhos é que são considerados fracos, quase cegos.

Além disso, na sequência (509b2-4), diz Sócrates que o que proporciona aos visíveis sua gênese, crescimento e alimento é o sol. Sua luz não lhes proporciona apenas o poder de serem vistos (tèn tôे horâsthai dýnamin). Essa complementação é importante para compreendermos como, para Platáo, os sensíveis têm uma existência e um desenvolvimento no mundo que independe da percepçáo que temos deles. Embora nosso acesso a eles esteja circunscrito às diferentes maneiras de percebê-los, em momento algum, pelo menos nesse contexto do livro VI, o filósofo póe em dúvida sua realidade, ou, melhor dizendo, em momento algum ele póe em dúvida que essas coisas que nos aparecem, essas aparências ou percepçóes correspondam de fato a coisas exteriores a nós.

Poderíamos acrescentar a essas passagens uma do Timeu, 67d, em que as cores são explicadas como partículas que emanam das coisas na direção da corrente visual, e que são maiores, menores ou iguais em tamanho às partículas dessa corrente. $\mathrm{O}$ impacto entre elas corresponde a uma afecção específica, que é, por fim, uma cor. Não há nessa explicação nada que nos impeça de considerar a estrutura da corrente visual como comum aos homens, o que implicaria uma grande diferença com relação à tese protagórica do Teeteto, que analisaremos a seguir. De todo modo, parece-nos claro que no Timeu as cores têm um vínculo com coisas existentes e determinadas, embora as cores mesmas só surjam na relação entre coisas e homem que pode ver ${ }^{11}$.

\footnotetext{
${ }^{10}$ Platão prefere usar outro termo para significar as luzes que aparecem à noite, substituindo $p$ hôs, nele claramente associado à luz do Sol, por phénge, "luzes", "clarōes", para se referir à luz noturna. Essa seria uma forma de distinguir, pela linguagem, uma da outra. Nota ADAM (1980, v. 2, nota ad 508c19) que Platão sabia que a luz da lua não era própria, mas derivada do Sol, como se pode depreender de República, X, 616e.

${ }^{11}$ Embora Beare (1906, p. 54) esteja de acordo no que diz respeito ao Timeu, ele propóe uma leitura diferente da República, tomando por base o passo 508c, que fala de como as cores dependem da luz,
} 
Esse pressuposto da existência dos sensíveis é fundamental para a analogia com a visão inteligível, uma vez que as Ideias também devem ser tomadas como existentes independentemente de nosso conhecimento delas. $\mathrm{E}$ a noção de verdade (alétheia) que aparece nesse contexto, primeiro em 508d5 e depois em 508e1, está assentada numa representação dos inteligíveis como passíveis de maior ou menor conhecimento, dependendo da "posição" em que o homem que conhece se encontra com relação ao Bem. As Ideias não deixam de existir e de ser cognoscíveis em sua plenitude por nós não sermos capazes de vê-las. Porém, enquanto a noite, o sono e a vontade de piscar são incontornáveis, e somos privados, de fato, da visão dos sensíveis, os obstáculos para a visão dos inteligíveis é de outra ordem. São outras as noites e os entraves. Com efeito, a verdade, quando associada à luminosidade da Ideia de Bem, é mostrada como estável e referencial na apreciação das Ideias. "Estar na verdade", se é que podemos dizer assim, é estar em situação perfeita para ou na contemplação das Ideias. É como estar diante dos visíveis em plena luz do meio-dia. Metáfora que explica pouco, mas que é suficiente para estabelecermos um contraste com a teoria da visão que aparece atribuída ao Protágoras do Teeteto.

No Teeteto, a afirmação da existência de um sensível qualquer está condicionada à sua percepção por alguém. Ao menos essa parece ser a interpretaçáo que Platão dá à célebre formulação protagórica do homem-medida:

Pois diz que o homem é a medida de todas as coisas (pánton khremáton métron ánthropon eînai), das que são, que elas são (tôn mèn ónton hos ésti); das que não são, que elas não são (tòn dè mè ónton hos ouk éstin). (Teeteto, $152 \mathrm{a} 2-4)$.

Continua Sócrates, explicando o que ela quer dizer: "Como as coisas a mim aparecem, assim elas são para mim; como as coisas a ti aparecem, assim elas são para ti” (152a7-9).

em especial da luz do sol, para serem vistas. O autor alude a uma existência das cores na República dependente da phantasía, e não como provenientes das coisas mesmas. Mas o fato é que, por um lado, nada parecido com a noção de phantasía aparece nesse passo da República, e, por outro, a luz do dia também é indispensável para a visão, sempre visão de cores, também no Timeu, como se pode depreender da descrição do corpo homogêneo formado pela corrente visual e a luz do dia, e de sua desintegração com o chegar da noite. Parece-nos que ambos os textos são compatíveis, no sentido de que (i) as cores estão associadas a objetos existentes e (ii) de que a luz do dia é indispensável para que ocorra a visão dessas mesmas cores. 
Mais adiante (156a-c), apresenta Sócrates a arkhé, o princípio dessa teoria na forma de um mito (mûthos, segundo 156c3):

O todo era movimento e náo havia nada fora disso. E havia duas formas de movimento, cada um deles em quantidade infinita, um tendo o poder (dýnamin) de agir (poieîn), o outro de padecer (páskhein). A partir da junção destes e da fricção de um no outro nasce uma multidão infinita de filhos (éngona pléthei mèn ápeira), mas em pares de gêmeos (dídyma): um, o sensível, o outro, a sensação (tò mèn aisthetón, tò dè aísthesis), a qual sempre germina (synekpiptousa) e nasce (gennoméne) junto com o sensível. Assim essas nossas sensaçôes têm nomes (ékhousin onómata), como as chamadas visōes (ópseis), audiçōes (akoai), odores (osphréseis), frios (psýkheis), calores (kauiseis), prazeres (hedonaî), tristezas (lüpai), desejos (epithymiai), medos (phóboi) e outras, inumeráveis e anônimas, bem como são numerosíssimas as nomeadas. O gênero do sensível, por sua vez, é produzido ao mesmo tempo que cada uma dessas: para as visōes, cores, variadas as primeiras, variadas as últimas; para as audiçôes, do mesmo modo há os sons, e para as demais sensaçôes os demais sensíveis da mesma família nascem (syngenê gignómena).

Reparem como a geração dos sensíveis está atrelada à geração da sensação e vice-versa, considerados estes como pares de gêmeos nessa narrativa no estilo das Teogonias (cf. Diès, em PLATON, 1967, p. 178, n. 1). Para fora da percepção, nada é um em si e por si mesmo (hèn mèn autò kath' hautò oudén estin - 152d2-3), nada nunca é (ésti mèn gàr oudépot oudén - 152e1), porém sempre devém (aei dè gígnetai-152e1) ${ }^{12}$.

Se a origem dos sensíveis na República era conferida ao sol, no Teeteto a suposta doutrina de Protágoras relaciona a origem dos sensíveis à sua percepção por alguém. Isso implica que, mesmo que se veja na filosofia platônica uma herança das teorias do fluxo, no sentido de pensar os sensíveis no devir, em constante alteração, geração e perecimento, incognoscíveis por sua transitoriedade, diversidade e multiplicidade, por outro lado, ao confrontarmos a descrição dos sensíveis na República com a do Protágoras do Teeteto, alguma diferença deve ser marcada entre uma e outra interpretaçóes

12 Para o presente momento, não importa responder à questáo de se o relativismo de Protágoras é realista, no sentido de a percepção corresponder a uma determinada conformaçáo da matéria, ainda que altamente provisória, ou se é subjetivo, no sentido de a percepção não corresponder a nenhuma realidade exterior determinada, ainda que efêmera. De qualquer forma, o grau de mutabilidade que ele parece propor nâo permite falar em existência de nada determinado. Portanto, ainda que se advogue por um relativismo realista, a noção de verdade atribuída a Protágoras não perde sua complexidade, uma vez que ainda depende do encontro único de sensiente e sensível num determinado e irrecuperável instante. Mas o assunto é muito interessante e bem explorado por BROCHARD (1954, p. 23-33). 
não apenas da visão, mas dos sensíveis, do âmbito do devir. Embora não seja o caso de atribuir Ser aos sensíveis, Platão sinaliza com alguma realidade e determinação para eles ao falar de sua gênese e crescimento. Os sensíveis não são, portanto, meras aparências no sentido protagórico do termo. Eles não têm sua existência condicionada a um aparecer a alguém.

Quanto às consequências da teoria protagórica, no que concerne à verdade, elas serão categoricamente divergentes da platônica. Se a visão dos sensíveis em Platão dependia da luminosidade do sol, em Protágoras, a referência (ou o métron, se quisermos manter o vocabulário original) é aquele que percebe, tomando-se aquele que percebe não como o homem em geral, porém, o homem singular, que se encontra numa determinada condição, isto é, "este homem neste momento", já que esse que percebe é também sempre outro e outro, inserido também no devir, também não sendo ele mesmo algo estável ${ }^{13}$. Do encontro daquele que percebe com o movimento daquilo que chamamos sensíveis é gerada uma sensação única, que diferirá de outras de acordo com os sempre outros sensientes e sensíveis. Se não há referência para fora desse instante da percepção, "[...] verdadeiro para mim é minha sensação [...] e sou eu que decido [...] que as coisas que são para mim são, e que as que não são para mim não são" (160c7-9). Sócrates descreve ainda o percipiente como apseudés (que não mente, verídico, que não se engana; cf. BAILLY, 2000, p. 338) e como aquele cujo pensamento (diánoia) não fracassa, não falha (mè ptaion - 160d1).

\subsection{A ORGANIZAÇÁo DAS DIFERENTES PERCEPÇÓES PELA ALMA CORRESPONDE, DE FATO, À ORGANIZAÇÁOO DO SENSÍVEL}

O segundo pressuposto na imagem da visão como análoga ao conhecimento dos inteligíveis é este, o de não questionar se a maneira como percebemos a realidade sensível se lhes corresponde de fato. Em Platâo, como vimos anteriormente na interpretação do Sócrates do Teeteto e brevemente na República, os diferentes sensíveis são percebidos pelos órgãos dos sentidos específicos - as cores pela vista, os sons pelo ouvido etc. - e essas diferentes

\footnotetext{
${ }^{13}$ Beare (1906, p. 56) apresenta esse conflito entre Platáo e o Protágoras do Teeteto, quanto à existência dos sensíveis, mas desde a explicação acerca das cores. Ao que tudo indica, a tese protagórica - como Platão a descreve - não admite a possibilidade de uma estrutura perceptiva comum aos homens, algo de estável na maneira de perceber os sensíveis, nem admite nenhuma determinação, ou estabilidade de coisas existentes, com certas características etc. Daí que não se possa garantir a existência da brancura, ou que vejamos, mesmo nós homens, o mesmo branco. Nem o mesmo homem, em diferentes situaçóes e condiçōes, o veria. Cf. PLATÃO. Teeteto, 153e-154b e 156d-157c.
} 
percepçôes são encaminhadas para e organizadas pela alma, que identifica, por exemplo, como um e mesmo aquela coisa que posso ver e ouvir. Platão não se pergunta, todavia, se isso que estamos chamando de percepção organizada (BEARE, 1906, p. 262 e 276, p. ex., usa o termo synthesis para dizer o mesmo), se essa imagem ou representação que formo da coisa, já na alma, realmente corresponde à coisa como de fato é. Não se trata mais de saber se os sensíveis são, independentemente da percepção, mas se são tais quais percebidos em sua inteireza.

Questionando esse pressuposto na analogia com os inteligíveis, teríamos o bizarro resultado de que é possível que, ao julgarmos que conhecemos ou contemplamos as Ideias, na verdade não as conhecemos tais quais elas são, não havendo vínculo seguro entre nosso pensamento e a realidade das Ideias.

A interpretação de Protágoras no Teeteto já seria suficiente para criar esse conflito, por náo se poder falar, segundo nossa leitura, de coisas que são independentemente de alguém que percebe. Entretanto, há outra argumentação, não contemporânea a Platão, todavia, que estabelece um confronto muito interessante com ele, embora lhe não seja dirigida especificamente, mas a essa postura, que é a do senso comum, de não duvidar de que o mundo seja tal qual percebido. Essa argumentação é a do terceiro dos modos céticos para a suspensão do juízo, que vamos ler na versão das Hipotiposes Pirrônicas de Sexto Empírico.

Esse modo trata do desacordo entre os diferentes órgãos dos sentidos (I, 91-100). Entre os exemplos de Sexto estão a pintura, que parece aos olhos ter profundidade, mas não ao toque; o mel, que parece agradável à língua, mas desagradável aos olhos. Não seríamos, então, capazes de dizer como são essas coisas por natureza, embora possamos dizer como elas parecem ser em determinada ocasião.

Até aí o argumento é pouco persuasivo e o próprio Aristóteles na Metafísica (IV, 1010b15-25) já o teria derrubado com a ideia de que cada sensível é percebido pelo seu sentido próprio e que o engano advém do fato de proferirmos um juízo com base na percepçáo de algo por um sentido inadequado. Dessa forma, o sentido que nos ajudaria a julgar o sabor do mel é o paladar e não a vista, assim como o sentido que nos ajudaria a julgar as relaçôes de profundidade numa superfície seria o tato e náo a vista.

Porém, a exposição desse modo por Sexto não termina assim. Ao introduzir o exemplo da maçã, o filósofo entra justamente na questáo que ora 
nos inquieta. Uma maçã é macia, cheirosa, doce e amarela, segundo Sexto. O que não é claro é: (i) se a maçã tem apenas essas qualidades (poiótetas); (ii) se a maçã tem apenas uma qualidade, que aparece variada para os diferentes órgãos dos sentidos ou (iii) se a maçã tem mais qualidades que as aparentes para nós. Posta de outra maneira, a questão é a seguinte: sabemos que somos dotados de cinco sentidos. Mas o que nos assegura que haja também cinco qualidades sensíveis? Será que não há nenhuma qualidade sensível que escape aos nossos sentidos? Essa é uma questão que parece não ter tocado a Platão, mas que já ocorre em Aristóteles e em Epiteto (segundo ANNAS; BARNES, 1997, p. 75), e séculos depois é um problema enfrentado por alguns filósofos modernos (por exemplo, Descartes, nas Meditaçóes - em especial $\$ 21$ da Meditação Sexta). Conhecida como a questáo da comensurabilidade dos sentidos, ela vai interessar especialmente aos filósofos da representação, imersos no problema de se o mundo percebido corresponde de fato à realidade exterior.

\section{Conclusão E APONTAMENTo de OUTRAs QUeSTÓES}

Embora essa última questão não apareça em Platão, não lhe ocorra como um problema, ela enseja uma reflexáo sobre a imagem utilizada para sua explicação acerca do Bem e do conhecimento das Ideias que faz balançar aquele que passa por cima dela (dessa imagem) com uma leitura rápida e descompromissada. Se é a visáo uma metáfora privilegiada pelo autor para descrever o processo de conhecimento (atentemos para quantas vezes ela ocorre na República), é preciso recuarmos um pouco para compreendermos o que, afinal, Platão entende por ela, os pressupostos que essa compreensão envolve e o tipo de refutação que ela pode enfrentar. Esse foi nosso objetivo no desenvolvimento deste trabalho.

Cabe assinalar, todavia, que muito falta para uma compreensão completa do que seria a visão para Platão. Isso porque, embora o filósofo explique como a visão se dê, ele se refere à visão das cores, à afecção corporal que é encaminhada à alma. Mas em momento algum fica claro como a alma opera a reunião das diversas afecçôes corporais. E o fato é que não experimento ver cores. Vejo coisas, que reconheço como distintas, existentes, dotadas de certas qualidades etc. Tudo isso já não é mais puramente a visão, rigorosamente falando. Isso que nós reconhecemos na linguagem ordinária como "ver" não se identifica absolutamente com a descrição platônica da visão, ou mesmo, arrisco dizer, com a de qualquer pensador. Crombie (1967, v. 2, p. 2-3) é 
da mesma opinião e apresenta uma formulação que, embora não esteja em Platão textualmente, ilustra bem o que queremos dizer: devemos distinguir, ao considerar a percepção, o quadro cognitivo do quadro causal. Conforme o quadro cognitivo, usamos nossos sentidos para descobrir como as coisas são. De acordo com o quadro causal, por outro lado, os dados sensoriais são somente os resultados do estímulo de nossos órgãos sensoriais. Em Platão, segundo Crombie, é o segundo quadro que se desenha.

Que relação, porém, é estabelecida entre a percepção visual, desde o quadro causal, e a visão como visão de coisas não fica absolutamente claro (cf., sobre essa lacuna, BRISSON, 1974, p. 441, e BEARE, 1906, p. 46, 214-215, 275-276). E é por isso que a passagem para a linha dividida precisa ser feita. Pois, embora a visão dos inteligíveis esteja sendo na República explicada em função da imagem da visão dos sensíveis, os próprios inteligíveis são anteriores e imprescindíveis para a última. Não podemos sequer imaginar, elucubrar, dentro do quadro platônico, o que seria ver, e aí estamos nos referindo à visão sensível mesmo, sem os inteligíveis. Afinal, quando me dou conta ou digo para mim mesma "vejo um homem", o que de fato ocorre? A resposta que essa pergunta pede não é do âmbito, ou somente do âmbito, da visão sensível. Como se dá a passagem da percepção específica de cada sentido para aquilo que de fato me aparece, tà phainómena? E se as coisas me aparecem dotadas de algum sentido - "vejo um homem", "ali fora tem várias árvores”, por exemplo -, como não reconhecer na visão dos sensíveis já algum aspecto cognitivo, ainda que circunscrito (talvez) à dóxa?

Há uma passagem do Timeu (64b) que apenas alimenta essas últimas questôes, e que não gostaríamos de omitir, embora não tenhamos capacidade para analisá-la e "resolvê-la" agora. Vamos deixá-la como indicadora de nossa dúvida sobre a relaçáo entre a visão de coisas e o conhecimento (em algum grau):

Pois o muito móbil por natureza (katà phýsin eukineton), quando uma breve afecção (brakhù páthos) recai sobre ele, suas diferentes partes a transmitem de uma a outra em círculo, atuando sobre ela, até que, chegando ao discernimento (tò phrónimon), reporte o poder do agente (exangeílei tôे poiésantos tèn dýnamin).

Para contextualizar a passagem, esse é um momento em que Timeu deseja explicar por que algumas partes de nosso corpo são afetadas por outros corpos e outras não. Essas últimas têm como exemplo o cabelo. Se alguém aperta ou corta o cabelo de alguém, este não é afetado, não se experimenta nenhuma 
sensação por isso, porque as partes do cabelo, constituídas em sua maior parte de terra, e por isso pouco móveis, não transmitem a afecção do cabelo para a alma. Já a corrente visual tem como elemento preponderante o fogo, um eukineton, algo muito móvel e, por isso, há transmissão daquilo que a afeta para a alma. O surpreendente da passagem é que aqui, extraordinariamente, Platão não fala simplesmente num encaminhamento das afecçóes para a alma, psykhé, mas para tò phrónimon, fazendo referência a uma instância da alma cujo nome remete a "discernimento", "sagacidade", "sabedoria”, "reflexão". É claro que a passagem não é suficiente para corroborar nossa hipótese de uma vinculação necessária entre visão sensível e o conhecimento ${ }^{14}$ (sempre "em algum grau”). Contudo, se ela não indica um caminho, ela permanece como um problema para quem defender uma radical dissociação entre essas duas instâncias.

HADDAD, Alice Bitencourt. Sensory vision as an image of the vision of ideas. Trans/Form/ Ação, Marília, v. 35, n. 3, p. 3-20, Set./Dez., 2012.

ABSTRACT: This paper aims to explain what Plato means in the Republic by "sight" (opsis), a concept used by the philosopher as an image that can help us to understand what he means by knowledge of Ideas.

KEYWORDS: Plato. Republic. Sight. Perception.

\section{REFERÊNCIAS}

ADAM, J. The Republic of Plato. 2nd ed. Cambridge: Cambridge University Press, 1980. v. 2. ANNAS, J.; BARNES, J. The Modes of Scepticism: Ancient Texts and Modern Interpretations Cambridge: Cambridge University Press, 1997.

ARCHER-HIND, R. D. (Ed.). The Timaeus of Plato. North Stratford: Ayer Company, 2002. $1^{\text {a }}$ ed. de 1888 .

14 Essa também é proposta por Beare (1906), que mostra, em seu capítulo intitulado "sensus communis", diversas passagens no Timeu e no Teeteto que dão a entender, ainda que de maneira pouca clara, que a síntese dos dados da percepçáo é funçấo do que ele chama de atividade do entendimento (activity of understanding). Ver essa conclusão, principalmente, ao final do capítulo, entre as p. 275276. Em Platão, o termo traduzido por entendimento é tò phrónimon, como ora apontamos. 
ARISTÓTELES. De Anima: Livros I, II e III. Apresentação, tradução e notas de Maria Cecília Gomes dos Reis. São Paulo: Ed. 34, 2007.

BAILLY, A. Dictionnaire Grec-Français. Rédigé avec le concours de E. Egger. Édition revue par L. Séchan et P. Chantraine, avec, en appendice, de nouvelles notices de mythologie et religion par L. Séchan. Paris: Hachette, 2000.

BEARE, J. I. Greek Theories of Elementary Cognition from Alcmaeon to Aristotle. Oxford: Clarendon Press, 1906.

BRISSON, L. Le Même et l'Autre dans la Structure Ontologique du Timée de Platon: Un commentaire systématique du Timée de Platon. Paris: Klincksieck, 1974.

BROCHARD, Victor. Protagoras et Démocrite. Études de Philosophie Ancienne et de Philosophie Moderne. Paris: Vrin, 1954. p. 23-33.

CORNFORD, F. M. Plato's Cosmology: The Timaeus of Plato. Indianapolis: Bobbs-Merril, [1937?].

CROMBIE, I. M. Plato’s Doctrines. London: Routledge \& Kegan Paul, 1967. v. 2.

PLATÃO. Timeu-Critias, O Segundo Alcibiades, Hipias Menor. Tradução direta do grego de Carlos Alberto Nunes. 3. ed. Belém: UFPA, 2001.

PLATON. La République: Livres IV-VII. Texte établi et traduit par Émile Chambry. Paris: Les Belles Lettres, 1946. (Collection des Universités de France, Platon, t. 7, 1re partie).

. Théétète. Texte établi et traduit par Auguste Diès. Paris: Les Belles Lettres, 1967. (Collection des Universités de France, Platon, t. 8, 2e partie).

. Timée-Critias. Texte établi et traduit par Albert Rivaud. Paris: Les Belles Lettres, 1985. (Collection des Universités de France, Platon, t. 10).

- Timée, Critias. Traduction inédite, introduction et notes par Luc Brisson avec la collaboration de Michel Patillon pour la traduction, avec un Supplément bibliographique 1995-2000. 5e ed. Paris: GF Flammarion, 2001.

SEXTUS EMPIRICUS. Outlines of Pyrrhonism. With an English translation by R. G. Bury. Cambridge MA: Harvard University Press, 1933.

Recebido em: 02.01.2012

Aceito em: 03.03.2012 
$H A D D A D, A . B$. 